\title{
The Unsuccessful Self-treatment of a Case of 'Writer's Block': A Replication in Science Education
}

Georgios Ampatzidis ${ }^{1}$

Received 28 August, 2021

Accepted 8 October, 2021

Published 24 November, 2021

Issued 3 March, 2022

Correspondence

ampatzidis.georgios@ac.eap.gr

License (a) (1)

This article is icensed under the Creative Commons Attirbutio 4.0 (CC-BY 4.0) license, which

allows you to copy, redistribute

article and all its contents in any

medium or format for any

purpose, provided that

appropriate credit is given

(c) Ampatzidis 2021

A) Check for updates 


\section{References}

Artino, R. A. Jr. (2016). The unsuccessful treatment of a case of 'Writer's Block': A replication in medical education. Medical Education, 50(12), 1262-1263. https://doi.org/10/gnkd3q

Hermann, P. B. (1984). Unsuccessful self-treatment of a case of "Writer's Block": A partial failure to replicate. Perceptual and Motor Skills, 58(2), 350-350. https://doi.org/10.2466/pms.1984.58.2.350

Makel, C. M., \& Plucker, A. J. (2014). Facts are more important than novelty: Replication in the education sciences. Educational Researcher, 43(6), 304-316. https://doi.org/10.3102/0013189x14545513

Molloy, G. N. (1983). The unsuccessful self-treatment of a case of "Writer's Block": A replication. Perceptual and Motor Skills, 57(2), 566-566. https://doi.org/10.2466/pms.1983.57.2.566

Upper, D. (1974). The unsuccessful self-treatment of a case of "writer's block. Journal of Applied Behavior Analysis, 7(3), 497. https://doi.org/10.1901/jaba.1974.7-497a 